\title{
Atosiban vs. ritodrine as a tocolytic in external cephalic version at term: a prospective cohort study
}

\author{
Jorge Burgos*, Nekane Eguiguren, Eider Quintana, \\ Patricia Cobos, Maria del Mar Centeno, Rosa \\ Larrieta and Luis Fernández-Llebrez
}

Department of Obstetrics and Gynecology, Cruces University Hospital, Baracaldo, Vizcaya, Spain

\begin{abstract}
Objective: To compare the success rate of external cephalic version (ECV) at term using ritodrine or atosiban as a tocolytic agent.

Study design: Prospective cohort study with a sample of 236 pregnant women with a breech presentation at term, from November 2006 to March 2008. Data have been analyzed from the moment the cephalic version is performed until the time of delivery.

Results: ECV success rate using ritodrine as a tocolytic agent was $56.8 \%$ compared to $31.4 \%$ with atosiban. Ritodrine increases the version success potential more significantly than atosiban $(\mathrm{P}<0.05)$. In both cases, the use of ECV reduced the rate of cesarean sections, although a higher number of versions are required with atosiban [numbers needed to treat $(\mathrm{NNT})=9.08$ ] to avoid a cesarean section compared to ritodrine $(\mathrm{NNT}=3.41)$.

Conclusions: Ritodrine seems better than atosiban as tocolytic agent for ECVs.
\end{abstract}

Keywords: Breech presentation; external cephalic version (ECV); ritodrine; tocolityc agents; vasotocin.

\section{Introduction}

Breech presentation occurs in 3-4\% of gestations at term. The preferred mode of delivery has changed throughout the years and after the publication of the term breech trial [17], the preferred option has been to perform elective cesarean sections with the aim of reducing perinatal morbidity and mortality at the cost of increasing the cesarean section rate and thus, maternal morbidity and mortality.

\footnotetext{
*Corresponding author:

Jorge Burgos San Cristóbal, MD

Departamento Obstetricia y Ginecología

Hospital de Cruces

C/Plaza de Cruces sn

48903 Baracaldo

Vizcaya

Spain

E-mail: jburgoss@sego.es
}

External cephalic version (ECV) is a procedure used to rotate the fetal presenting part from breech to cephalic through a series of external maneuvers. This procedure, which has been known for many years now, has received much attention in recent times because it reduces breech presentation at delivery and consequently the rate of cesarean sections. For this very reason, the major scientific societies $[3,16,23]$ recommend the use of this procedure in routine clinical practice.

A review [2] reports that tocolysis during the procedure increases the success rate of cephalic versions at term, betamimetics being the most widely studied drugs. More recently, modern drugs have shown tocolytic efficacy in premature labor with fewer side effects. Based on the low rate of side effects, selective antagonists of oxytocin (i.e., atosiban) are currently the preferred option. The purpose of this study is to compare the success rate of ECV at term using ritodrine or atosiban as tocolytic agent.

\section{Materials and methods}

A prospective cohort study was performed between November 2006 and March 2008 at our hospital. This procedure was offered to all patients with singleton breech-presenting gestations at term, provided there were no contraindications. Exclusion criteria to the use of ECV in our hospital include placenta previa, premature placental abruption, oligohydramnios [amniotic fluid index (AFI) <5], signs of fetal compromise, fetal death, severe malformations, multiples, isoimmunization, coagulation disorders and indication of cesarean section not related to fetal presentation.

All patients were informed in detail about the procedure, explaining the benefits and risks. Upon admission, before the procedure, an obstetric ultrasound is performed to confirm presentation on the day of the ECV and to determine fetal weight and placental location, breech variety and amount of amniotic fluid. Prior to ECV, a cardiotocography (CTG) was performed for 20 min to confirm fetal well-being. The technique is performed in the delivery unit, on an empty stomach, under tocolysis and with ultrasonographic and CTG supervision. Anesthesia and immediate operative facilities were available in case an emergency cesarean section was required. Our hospital's protocol approved the use of either one of these tocolytics, except in the case of patients with contraindications to the use of betamimetics, which does not apply to any of the patients of the cohorts. Ritodrine (Prepar, Laboratorios Reig Jofre SA, Spain) was administered via continuous $200 \mu \mathrm{g}$ infusion pump starting $30 \mathrm{~min}$ before the version and is maintained during the maneuver; and atosiban (Tractocile, Laboratorios Ferring SA, Spain) is administered intravenously in a single $0.9 \mathrm{~mL}$ bolus only 2 min before the technique is applied. The ECVs were always performed by the same two obstetricians. 
After the version attempt, a continuous CTG is done during a total of 60 min to verify fetal status and the presence of side effect in patients. Anti-D was also administered if indicated. If no further complications arise, the patient is discharged. The procedure is considered to be successful if there is a rotation from breech to cephalic presentation. Subsequently, patients are monitored until the moment of delivery by examining obstetric variables (i.e., presentation at delivery, incidence of cesarean section, instrumental delivery rate) as well as perinatal results (incidence of neonatal Apgar scores $<7$ at $5 \mathrm{~min}$, mean cord arterial $\mathrm{pH}$, neonatal intensive cares unit admission rate).

The two obstetricians who perform the versions are the ones to decide which drug shall be used. Data regarding all versions performed until March $2008(\mathrm{n}=320)$ were collected since November 2006. In March 2008, the cases belonging to each cohort were defined by means of a computer-based allocation of the total number of versions performed. The analysis yielded a 1:1 ratio and similar rates of the factors associated with the success (i.e., parity, previous cesarean section, gestational weeks, breech type, placental location, amniotic fluid and estimated fetal weight).

To detect a $20 \%$ difference in the success rate against our baseline success rate, which was $55 \%$, with a power of $80 \%(a=0.05)$, a minimum of 110 women are needed in each group. A total of 118 cases were finally selected in each cohort $(n=236)$. Dichotomous data were evaluated by the Pearson's $\chi^{2}$-test and continuous data were analyzed by Student's $t$-test. The statistical analysis has been applied with the SPSS v15 program. Significance was set at a $\mathrm{P}<0.05$.

\section{Results}

Table 1 shows the characteristics of the two cohorts, each comprising 118 patients. Both cohorts were relatively homogenous in nature, i.e., similar parity, placental location and breech type. Follow-up was available on all women.

In the atosiban cohort, breech presentation was modified to cephalic presentation in a total of 37 patients $(31.4 \%$ success rate) as opposed to 67 patients in the ritodrine cohort (56.8\% success rate, $\mathrm{P}<0.05)$.

Five complications have been registered after the use of $\mathrm{ECV}$, all of which occurred with ritodrine. There were three episodes of vaginal hemorrhage (two after an unsuccessful attempt and one after a successful version), which is why a cesarean section was finally performed in these three cases. In another patient, a non-reassuring cardiotocographic tracing was detected after a successful cephalic version. It was then decided to terminate pregnancy via induction and the delivery ended with a cesarean section by secondary arrest of dilatation due to fetal malposition with a good perinatal outcome. None of the four infants had to be transferred to the neonatal unit and all were discharged without further complications. Lastly, another patient showed signs of dyspnea, dizziness and perspiration after the ritodrine infusion. The chest X-ray showed signs compatible with acute pul-

Table 1 Clinical and demographics characteristics of the study population.

\begin{tabular}{|c|c|c|c|}
\hline & Atosiban $(\mathrm{n}=118)$ & Ritodrine $(\mathrm{n}=118)$ & P-value \\
\hline Age of women & $32.20 \pm 4.30$ & $32.48 \pm 4.35$ & 0.99 \\
\hline \multicolumn{4}{|l|}{ Parity } \\
\hline Nulliparous & $84(71.2 \%)$ & $83(70.9 \%)$ & \multirow[t]{4}{*}{0.96} \\
\hline Parous-1 & $30(25.4 \%)$ & $31(26.5 \%)$ & \\
\hline Parous-2+ & $4(3.4 \%)$ & $3(2.6 \%)$ & \\
\hline Previous cesarean section & $4(3.4 \%)$ & $5(4.3 \%)$ & \\
\hline \multicolumn{4}{|l|}{ Weeks in ECV } \\
\hline 37 weeks & $97(82.2 \%)$ & $95(81.2 \%)$ & \multirow[t]{5}{*}{0.44} \\
\hline 38 weeks & $16(13.6 \%)$ & $13(11.1 \%)$ & \\
\hline 39 weeks & $5(4.2 \%)$ & $7(6 \%)$ & \\
\hline 40 weeks & $0(0 \%)$ & $2(1.7 \%)$ & \\
\hline Missing & & 1 & \\
\hline \multicolumn{4}{|l|}{ Placental location } \\
\hline Anterior & $40(33.9 \%)$ & $39(33.3 \%)$ & \multirow[t]{4}{*}{0.99} \\
\hline Posterior & $65(55.1 \%)$ & $62(53 \%)$ & \\
\hline Fundal - lateral & $13(11 \%)$ & $12(10.2 \%)$ & \\
\hline Missing & & 5 & \\
\hline \multicolumn{4}{|l|}{ Breech variety } \\
\hline Frank & $79(66.9 \%)$ & $70(59.8 \%)$ & \multirow[t]{4}{*}{0.12} \\
\hline Complete - double footling & $28(23.7 \%)$ & $40(34.2 \%)$ & \\
\hline Incomplete & $11(9.4 \%)$ & $6(5.1 \%)$ & \\
\hline Missing & & 2 & \\
\hline \multicolumn{4}{|l|}{ Amount of fluid } \\
\hline Normal & $111(94.1 \%)$ & $105(89.7 \%)$ & \multirow[t]{4}{*}{0.15} \\
\hline Scarce (AFI 5-8) & $6(5.1 \%)$ & $6(5.1 \%)$ & \\
\hline Abundant & $1(0.8 \%)$ & $6(5.1 \%)$ & \\
\hline Missing & & 1 & \\
\hline Estimated fetal weight $(\mathrm{g})$ & $2.939 \pm 331$ & $2.948 \pm 357$ & 0.84 \\
\hline
\end{tabular}

Values are presented as $\mathrm{n}(\%)$ and mean \pm standard deviation (SD).

$\mathrm{ECV}=$ external cephalic version; $\mathrm{AFI}=$ amniotic fluid index. 
monary edema. The patient improved after treatment with furosemide and potassium. After a eutocic vaginal delivery with cephalic presentation, the newborn was admitted to the neonatal unit due to upper and lower limb deformity with ankylosis and was then discharged with a sensory-motor myelinizing polyneuropathy.

Figures 1 and 2 show the outcomes of both groups from the moment the version is performed until the time of delivery. As indicated, the fetal presentation rate remained constant from the version to the time of labor, including spontaneous reversions to breech presentation as well as the spontaneous versions to cephalic position. The cesarean section rate with ritodrine was $36.4 \%$, compared to $57.6 \%$ with atosiban, $\mathrm{P}<0.05$.

The number of versions that had to be performed in our hospital with ritodrine in order to avoid breech presentation at labor was 1.84 (95\% CI 1.57-2.23) as compared to 3.37
(95\% CI 2.59-4.82) with atosiban. Moreover, a total of 9.08 versions (95\% CI 4.30-82.45) were required with atosiban in order to avoid cesarean sections, as compared to 3.41 (95\% CI 2.49-5.41) with ritodrine.

Perinatal results are shown in Table 2. No significant differences were identified with regards to the 5-min Apgar scores $<7$, umbilical cord $\mathrm{pH}<7.10$ and neonatal admission rate. No complication was observed in infants associated with ECV.

\section{Discussion}

The use of ECV is an efficient way of reducing breech presentations at delivery as well as the cesarean section rate in this group of patients. A recent Cochrane review [2] concludes that tocolysis during the procedure increases the suc-

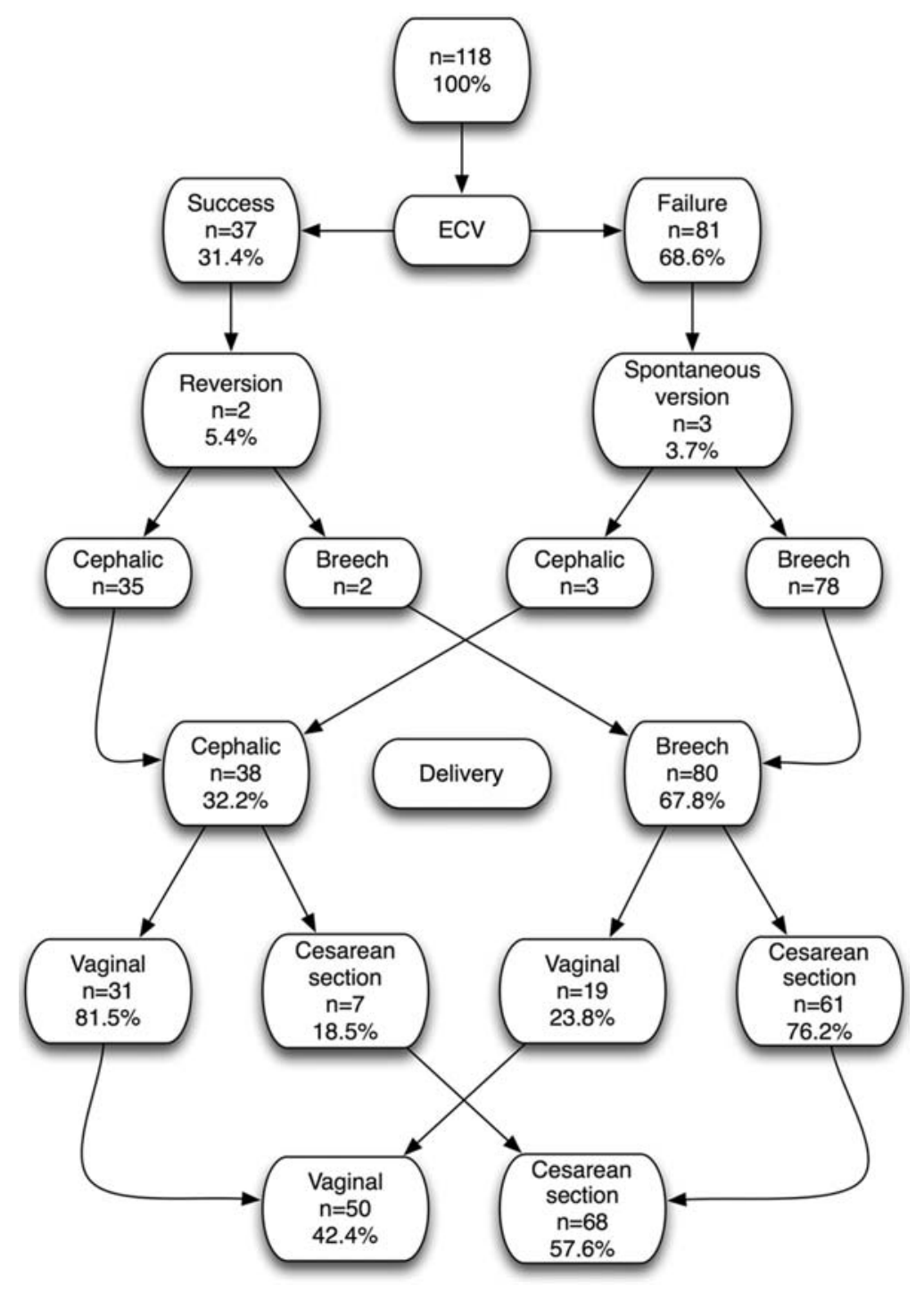

Figure 1 Evolution from atosiban cohort from ECV to delivery. Values are presented as $\mathrm{n}(\%)$; ECV $=$ external cephalic version. 


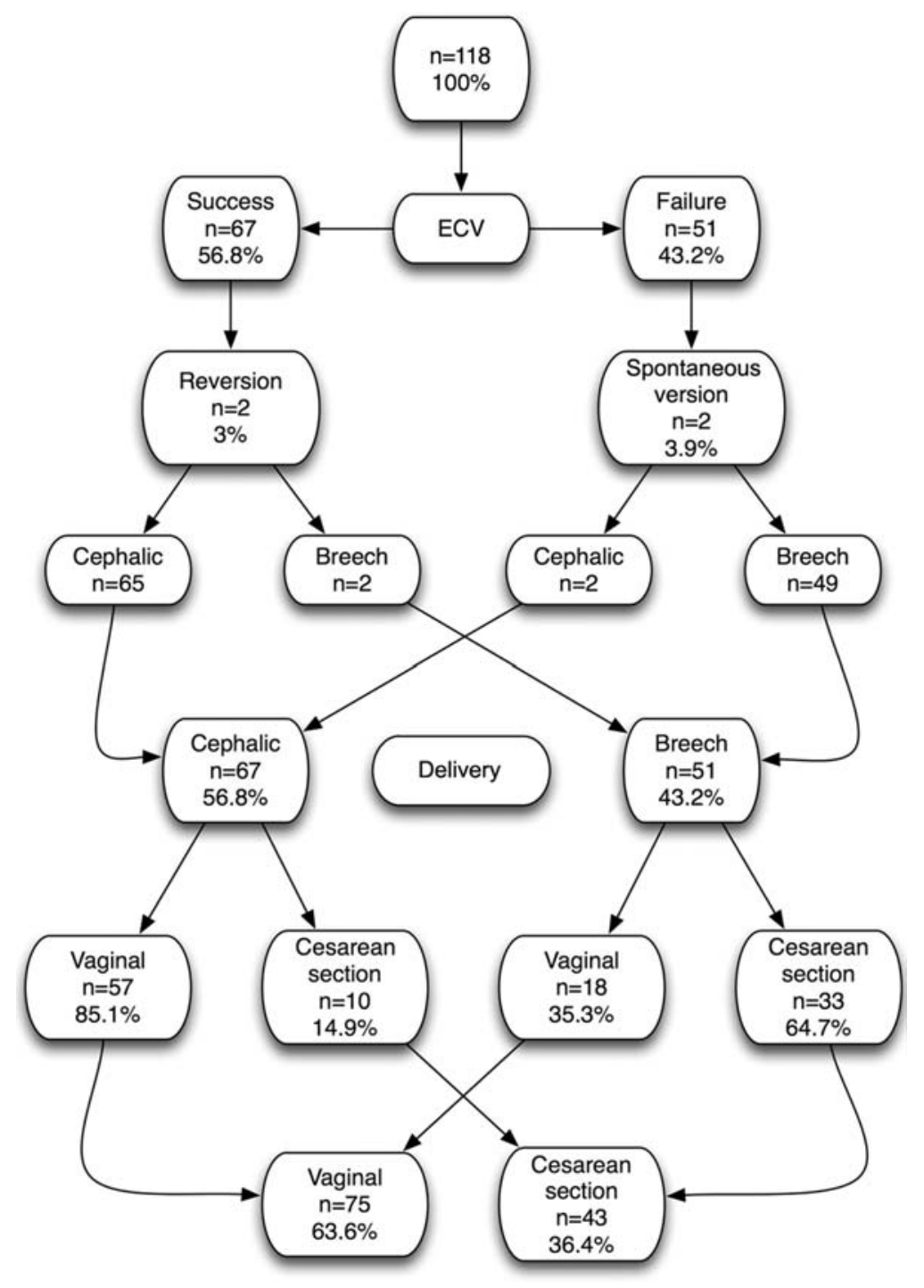

Figure 2 Evolution from ritodrine cohort from ECV to delivery. Values are presented as n (\%); ECV =external cephalic version.

cess rate of cephalic versions at term. The purpose of this study is to compare the success rate of ECV at term using ritodrine or atosiban as tocolytic agent.

The characteristics of both cohorts in our study, as specified in Table 1, are very similar to the variables studied and no significant differences were identified in the variables involved in the version success rate, i.e., parity, breech variety, placental location $[4,7,8,10,11]$.
Several studies have shown the efficacy of atosiban in the treatment of preterm labor [1, 5, 6, 21] but only one has studied it in the ECV procedure [12]. The study concludes that there are no significant differences between atosiban and ritodrine, although the results, as suggested by the authors, should be interpreted with caution due to the study design and sample size: a retrospective study in which the two cohorts have been selected in different years, and the initial

Table 2 Perinatal results.

\begin{tabular}{llll}
\hline & Atosiban & Ritodrine & P-value \\
\hline Apgar $<7$ at $5 \mathrm{~min}$ & $2(1.7 \%)$ & $2(1.7 \%)$ & NS \\
Mean cord arterial $\mathrm{pH}<7.10$ & $5(4.3 \%)$ & $4(3.4 \%)$ & NS \\
Neonatal intensive care unit admission rate & $5(4.3 \%)$ & $4(3.4 \%)$ & NS \\
\hline
\end{tabular}

Values are presented as $\mathrm{n}(\%)$.

$\mathrm{NS}=$ no significance. 
sample size was limited, 21 in the atosiban cohort and 17 in the ritodrine cohort, with a high rate of spontaneous versions before the maneuver (11 cases).

According to our protocol, ritodrine is administered via continuous $200 \mu \mathrm{g}$ infusion pump starting $30 \mathrm{~min}$ before the version is practiced and is maintained during the procedure, whereas atosiban is administered in a single bolus dose of $0.9 \mathrm{~mL}$ only $2 \mathrm{~min}$ before the procedure. Several studies have examined the acute tocolytic effect of atosiban, with the same bolus dose, namely in intralabor scenarios in gestations at term $[9,13,18]$. These studies conclude that both drugs have the same acute tocolytic potential, although betamimetics have a higher rate of side effects.

In view of our results, atosiban success rate $(31.4 \%)$ is significantly lower than ritodrine $(56.8 \%)$. Given this difference in the success rate, the rate of cesarean sections in the atosiban cohort $(57.6 \%)$ was significantly higher than that of ritodrine $(36.4 \%)$. According to the data published success rates of atosiban are very similar to those described for groups in which no tocolysis is performed [19, 20, 24], suggesting that the desired tocolytic effect has not been produced.

Beta-adrenergic agonists, like ritodrine, stimulate the adrenergic receptors involved in the autonomous regulation of uterine contraction. Thus, they activate adenylate cyclase by increasing cyclic adenosine mono-phosphate concentration, which leads to a reduction in the amount of calcium available, together with an inhibition of the myosin light-chain kinase. Antagonists of oxytocin, like atosiban, act as a selective competitive inhibitor of oxytocin receptors involved in the hormonal regulation of uterine contraction. Inhibiting the activation of the receptor means that there is no activation of phosphatidinositol, which stimulates calcium contraction via secondary messengers and thus, the activation of the myosin light-chain kinase [15]. Although the end effect of both drugs is the same, the mechanism of action is different. Thus, the potential of atosiban in ECV will be very low, which would explain why success rates are very similar to those obtained for those groups in which the version was performed without tocolysis.

Several studies confirmed that atosiban has a good safety profile whereas clinical signs of cardiovascular distress are relatively common in women treated with ritodrine $[14,22]$. In our study, all of the adverse events were observed in the ritodrine group $(4.23 \%)$, but none were associated with adverse perinatal outcomes, and clinical signs of cardiovascular distress were only in one woman $(0.84 \%)$.

Finally, the number of patients in which a version should be performed in order to avoid a cesarean section is almost three times higher with atosiban than with ritodrine. However, the numbers needed to treat (NNT) have been calculated in a hospital in which vaginal deliveries with breech presentation are done, which is why the NNT to avoid a cesarean is higher than in centers in which a cesarean is performed in most breech presentations.

In conclusion, ritodrine seems better than atosiban as a tocolytic agent in ECVs. Atosiban is an effective tocolytic agent that can be used in patients with contraindications or at high risk for ritodrine, although its beneficial tocolytic effect on the version should be examined in a randomized trials.

\section{References}

[1] Afschar P, Schöll W, Bader A, Bauer M, Winter R. A prospective randomised trial of atosiban versus hexoprenaline for acute tocolysis and intrauterine resuscitation. $\mathrm{Br} \mathrm{J}$ Obstet Gynaecol. 2004;111:316-8.

[2] Chan J, Cabrol D, Ingermarsson I, Marsal K, Moutquin JM, Fisk NM. Pragmatic comparison of b2-agonist side effects within the Worldwide Atosiban versus Beta Agonists Study. Eur J Obstet Gynecol Reprod Biol. 2006;128:135-41.

[3] De Heus R, Mulder EJ, Derks JB, Kurver PH, van Wolfswinkel L, Visser GH. A prospective randomized trial of acute tocolysis in term labour with atosiban or ritodrine. Eur J Obstet Gynecol Reprod Biol. 2008;139:139-45.

[4] External cephalic version. ACOG 2000. Available from: http://www.acog.org/.

[5] External cephalic versión for breech presentation. Guideline of SEGO (Obstetricians and Gynaecologists Society of Spain). SEGO 2001. Available from: http://www.sego.es/.

[6] External cephalic version guideline. RCOG Guidelines. 2006. Available from: http://www.rcog.org.uk/.

[7] Faron G, Vokaer A. Determining factors of the success of external cephalic version: a retrospective study of 439 cases. J Gynecol Obstet Biol Reprod (Paris). 2008;37:493-8.

[8] Ferguson JE, Armstrong MA, Dyson DC. Maternal and fetal factors affecting success of antepartum external cephalic version. Obstet Gynecol. 1987;70:722-5.

[9] Flock F, Stoz F, Paulus W, Scheurle B, Kreienberg R. External fetal version from breech presentation to cephalic presentation: modifying factors, reliability and risks. Zentralbl Gynakol. 1998;120:60-5.

[10] Giles W, Bisits A. Preterm labour. The present and future of tocolysis. Best Pract Res Clin Obstet Gynaecol. 2007;21: 857-68.

[11] Grootscholten K, Kok M, Oei SG, Mol BW, Van der Post JA. External cephalic version - related risks: a meta-analysis. Obstet Gynecol. 2008;112:1143-51.

[12] Hannah ME, Hannah WJ, Hewson SA, Hodnett ED, Saigal S, Willan AR. Planned cesarean section versus planned vaginal birth for breech presentation at term: a randomised multicentre trial. Term Breech Trial Collaborative Group. Lancet. 2000;356:1375-83.

[13] Hofmeyr GJ. Interventions to help external cephalic version for breech presentation at term. Cochrane Database Syst Rev. 2004:CD000184.

[14] Impey L, Lissoni D. Outcome of external cephalic version after 36 weeks' gestation without tocolysis. J Matern Fetal Med. 1999;8:203-7.

[15] Lamont RF. A quality assessment tool to evaluate tocolytic studies. Br J Obstet Gynecol. 2006;113(Suppl 3):96-9.

[16] Lurie S, Sadan O, Ben Aroya Z, Glezerman M. Atosiban treatment for uterine hyperactivity during active labor: a pilot study. J Perinat Med. 2004;32:137-9.

[17] Moutquin JM, Sherman D, Cohen H, Mohide PT, HochnerCelnikier D, Fejgin M, et al. Double-blind, randomized, controlled trial of atosiban and ritodrine in the treatment of 
preterm labor: a multicenter effectiveness and safety study. Am J Obstet Gynecol. 2000;182:1191-9.

[18] Newman RB, Peacock BS, VanDorsten JP, Hunt HH. Predicting success of external cephalic version. Am J Obstet Gynecol. 1993;169:245-9.

[19] Nor Azlin MI, Haliza H, Mahdy ZA, Anson I, Fahya MN, Jamil MA. Tocolysis in term breech external cephalic version. Int J Gynaecol Obstet. 2005;88:5-8.

[20] Rijnders M, Herschderfer K, Prins M, van Baaren R, van Veelen AJ, Schönbeck Y, et al. A retrospective study of the success, safety and effectiveness of external cephalic version without tocolysis in a specialised midwifery centre in the Netherlands. Midwifery. 2006;24:38-45.

[21] Shim J-Y, Park YW, Yoon BH, Cho YK, Yang JH, Lee Y, et al. Multicentre, parallel group, randomised, single-blind study of the safety and efficacy of atosiban versus ritodrine in the treatment of acute preterm labour in Korean women. Br J Obstet Gynaecol. 2006;113:1228-34.
[22] Stergiotou I, Talbot F, Yoong W. The use of atosiban and ritodrine in external cephalic version. Acta Obstet Gynecol Scand. 2007;86:927-9.

[23] Tocolitycs. Guideline of SEGO (Guideline of SEGO (Obstetricians and Gynaecologists Society of Spain). SEGO 2004. Available from: http://www.sego.es/.

[24] Worldwide Atosiban versus Beta-agonists Study Group. Effectiveness and safety of the oxytocin antagonist atosiban versus beta-adrenergic agonists in the treatment of preterm labour. The Worldwide Atosiban versus Beta-agonists Study Group. Br J Obstet Gynaecol. 2001;108:133-42.

The authors stated that there are no conflicts of interest regarding the publication of this article.

Received May 3, 2009. Revised June 4, 2009. Accepted August 3, 2009. 